This item was submitted to Loughborough's Research Repository by the author.

Items in Figshare are protected by copyright, with all rights reserved, unless otherwise indicated.

\title{
The importance of disaggregating within-person changes and individual differences among internalized motives, self-esteem and self-efficacy
}

\section{PLEASE CITE THE PUBLISHED VERSION}

http://dx.doi.org/10.1007/s11031-014-9466-6

\section{PUBLISHER}

(C) Springer

VERSION

AM (Accepted Manuscript)

\section{PUBLISHER STATEMENT}

This work is made available according to the conditions of the Creative Commons Attribution-NonCommercialNoDerivatives 4.0 International (CC BY-NC-ND 4.0) licence. Full details of this licence are available at: https://creativecommons.org/licenses/by-nc-nd/4.0/

\section{LICENCE}

CC BY-NC-ND 4.0

\section{REPOSITORY RECORD}

Cowan, Daryl T., and lan M. Taylor. 2019. "The Importance of Disaggregating Within-person Changes and Individual Differences Among Internalized Motives, Self-esteem and Self-efficacy”. figshare. https://hdl.handle.net/2134/17139. 
1 Running Head: WITHIN-PERSON AND BETWEEN-PERSON MOTIVATION

2

3

4

5

6

7

8

$9 \quad$ The importance of disaggregating within-person changes and individual differences among internalized motives, self-esteem and self-efficacy

11

12

13

14

Manuscript Submitted: $15^{\text {th }}$ January 2014

Manuscript Resubmitted: $7^{\text {th }}$ July 2014

15

Manuscript Resubmitted: $12^{\text {th }}$ December 2014

16

17

18

19

20

21

22

23 
Abstract

25 Grounded in self-determination theory, this study examined the implications of differentiating

26 between within-person weekly changes and between-person differences in average levels of

27 autonomy support and internalized motivation for one's self-esteem and self-efficacy. Thirty-

28 nine adults who were socially disadvantaged and unemployed completed weekly questionnaire

29 assessments over 11-weeks of a sports-based educational program. Multilevel modeling revealed

30 that within-person changes in perceptions of autonomy support positively predicted identified

31 regulation and introjected regulation; however, between-person differences in perceived

32 autonomy support predicted identified regulation only. Within-person changes in introjected

33 regulation positively predicted global self-esteem and self-efficacy towards future employment

34 in coaching; however, between-person differences in introjected regulation negatively predicted

35 self-esteem and self-efficacy. In contrast, within-person changes in identified regulation, as well

36 as between-person differences, were positively associated with self-efficacy. Between-person

37 differences in identified regulation also positively predicted self-esteem. It was also

38 demonstrated that many of these contrasting relationships are hidden if the different processes

39 are not disaggregated. As a result, we propose that different internalization processes exist which

40 depend on whether within-person changes or sustained levels of motivation are explored.

41

42 Key words: self-determination; autonomy; motivation; within-person; between-person. 
The importance of disaggregating within-person changes and individual differences among internalized motives, self-esteem and self-efficacy

Every day individuals take part in activities that are not carried out for inherent interest or enjoyment, but for extrinsic contingent outcomes associated with these activities. It is well known that the quality of these extrinsic motivations are important for long term adherence and persistence in many life domains, such as education, health, sport, work and personal relationships (Deci \& Ryan, 2008). However, one’s motivation toward an activity may also have important implications for one’s sense of self (Leary \& Baumeister, 2000). In the present study we demonstrate that the relationship between extrinsic motivation and self-evaluations is not straightforward due to the different repercussions of within-person changes and between-person differences in motivation toward an activity. Self-evaluation is a collective term reflecting individuals’ basic appraisals about his or her ability, competence and overall value (Bono \& Judge, 2003). The present study explores two distinct self-evaluations. Self-esteem refers to one’s global evaluation of his or her overall worthiness (Rosenberg, 1965), whereas, selfefficacy represents one's belief that he or she can be successful in specific contexts (Bandura, 1997). By exploring these two constructs we aimed to demonstrate the implications of holding different motives for global and contextual self-evaluations.

Organismic integration theory, one dimension of the wider self-determination theory, describes a process of internalization whereby external social sanctions which force action are converted into personally endorsed motives (Deci \& Ryan, 2000). When this internalization process is successful, an individual will be driven by identified regulation, which reflects motivation to participate in an activity because one values the associated outcomes (Ryan, 1993). Thus, identified regulations are relatively self-determined and autonomous (Deci \& Ryan, 2000). 
69 In contrast, introjected regulation manifests when the internalization process is prevented from occurring fully, either by a need-thwarting social context or dysfunctional intrapersonal

71 mechanisms (e.g., maladaptive cognitive schemas). Hence, reasons for behavior have been

72 somewhat internalized but have not become part of the self and, therefore, represent low levels

73 of self-determination (Deci \& Ryan, 2000). Examples of introjected regulations include taking

74 part in activities to prove self-worth or avoid guilt or shame for not taking part (Deci \& Ryan, $752000)^{1}$.

76 The tenet that both regulations have been internalized to different degrees (and, therefore, 77 reflect different levels of self-determination) suggests that they will lead to different cognitive, 78 affective and behavioral outcomes (Deci \& Ryan, 2008). For instance, in two studies of political 79 attitudes, identified regulation towards politics was positively related to actively seeking political 80 information, multifaceted political attitudes, and increased likelihood to vote. In contrast, 81 introjected regulation was positively related to relying on others for information, conflicting 82 emotions about political outcomes, and susceptibility to persuasion (Koestner, Losier, Vallerand,

83 \& Carducci, 1996). In education and sport contexts identified regulation has been shown to have 84 stronger associations with deep-level learning, adaptive affect and performance, compared to 85 introjected regulation (Assor, Vansteenkiste, \& Kaplan, 2009; Vansteenkiste, Simons, Lens, 86 Soenens, \& Matos, 2005).

87 Despite these suppositions, negative consequences of introjected regulation have not 88 always been observed. Pelletier, Fortier, Vallerand, and Brière (2001) reported no significant 89 differences in introjected regulation between behaviorally engaged competitive swimmers and 90 those who dropped out. In a systematic review of motivation, exercise, and physical activity, 91 introjected regulation was found to be positively associated with exercise-related benefits in 
92 many studies, with few studies reporting negative associations (Teixeira, Carraca, Markland,

93 Silva, \& Ryan, 2012). Regarding associations between introjected regulation and self-esteem,

94 theorists advocating self-esteem as a sociometer propose that motives to maintain one's value in 95 social circles (i.e., a form of introjected regulation) are closely associated with self-esteem and 96 are of evolutionary benefit (Leary \& Baumeister, 2000).

Some explanations for these mixed findings are apparent within the literature. For example, holding introjected motives with ‘approach’ characteristics (e.g., striving for self-

99 worth) may be more favorable, compared to ‘avoidance’ introjected motives (e.g., evading feelings of guilt; Assor et al., 2009). Temporal considerations may also be important, for

101 example, introjected regulation towards swimming was positively associated with behavioral 102 engagement 10 months later, but unrelated to engagement in the subsequent season (22 months

103 later; Pelletier et al., 2001). We propose a third explanation for the mixed findings pertaining to 104 introjected regulation; the distinction between short-term changes in motivation relative to an 105 individual's average levels (i.e., within-person changes) versus sustained between-person 106 differences in motivation toward an activity. We attempt to demonstrate that this discrepancy is 107 significant when exploring the internalization process and has important ramifications for self108 esteem and self-efficacy. Recently, Curran and Bauer (2011) explain that the psychological field has neglected to 110 differentiate between within-person changes and between-person processes and that 'these two 111 levels of influence can operate simultaneously and even in opposite directions' (pp. 2). Within112 person changes refer to short-term deviations from one's average levels. Extrapolating to the 113 internalization process, a within-person change in introjected motives may have some short-term 114 benefits for one’s self-esteem or self-efficacy. For example, striving to please others or avoid 
115 negative feelings more than one’s average levels may enhance feelings of self-esteem or efficacy

116 towards that specific activity at that point in time. Between-person differences reflect an

117 individual's average levels contrasted to other individuals. It is likely that sustained (i.e.,

118 average) levels of introjected motivation over a period of time enhances vulnerability to social

119 pressures, leads to an inauthentic existence and, thus, is detrimental for one's self-esteem or self-

120 efficacy (Ryan \& Brown, 2003). In contrast, both within-person changes (e.g., an increase in

121 perceived value of the activity from an individual's average levels) and between-person

122 differences (e.g., sustained worthiness of an activity) of identified regulation should hold positive

123 benefits because one's behavior is autonomous, volitional, and endorsed by the self (Deci \&

124 Ryan, 2000).

In addition to the influence of within-person changes versus between-person differences

126 in motivation on self-esteem and self-efficacy, it is of interest to explore the distinction between

127 within-person and between-person levels of contextual support for internalization processes (i.e.,

128 autonomy support). Autonomy support reflects a style of interacting with another individual that

129 embraces their needs and interests, allows them to find personal meaning in activity, and

130 encourages volitional functioning. A substantial amount of evidence demonstrates that autonomy

131 support is associated with self-determined motivation (e.g., Taylor \& Ntoumanis, 2007; Williams

132 \& Deci, 1996). Nonetheless, when an individual perceives a short-term increase in autonomy

133 support from a provider, relative to average levels, it is reasonable to suggest that the individual

134 may be more motivated to avoid the guilt of letting him or her down. In other words, a within-

135 person increase in perceptions of autonomy support may be associated with enhanced introjected

136 regulation. In contrast, sustained autonomy support should allow the individual to be less reliant

137 on the approval of others and ego-involved motives, that is, less driven by introjected regulation. 
138 Since autonomy support facilitates the internalization process (Deci \& Ryan, 1987; Williams \& 139 Deci, 1996), both within-person increases and average between-person differences in autonomy 140 support should be positively associated with identified regulation.

To summarize, we proposed that disaggregating within-person and between-person

142 influences of two different internalized motives has important implications for one’s self-esteem 143 and self-efficacy. We explored this notion within a group of socially disadvantaged adults who 144 were currently unemployed but attending a 12 hour per week sport and education program 145 prepared by a charitable organization. Self-esteem represents an important construct to 146 investigate in this sample because it can be severely damaged during periods of unemployment 147 (Harris et al., 2002). In addition, participants' self-efficacy regarding future coaching roles was 148 assessed because the program aimed to provide participants with the necessary skills and 149 qualifications to become employed as a sports coach (i.e., participants were being trained how to 150 coach). Previous research has found both constructs to be associated with job attainment (Eden 151 \& Aviram, 1993; Vinokur \& Schul, 1997) and their inclusion allowed us to explore distinct 152 global and contextual evaluations of the self. We hypothesized that within-person changes in perceived autonomy support from an

154 authority figure would be positively associated with identified and introjected regulation towards 155 program participation. Conversely, we expected that between-person differences in autonomy 156 support would be positively associated with identified regulation, but negatively predict 157 introjected regulation. Next, we hypothesized that within-person changes in identified and 158 introjected regulation would be positively associated with self-esteem and self-efficacy. 159 However, we expected that between-person differences in identified regulation would be 
160 positively associated with self-esteem and self-efficacy, whereas, between-person differences in 161 introjected regulation would be negatively associated with self-esteem and self-efficacy. Within each stage of our analysis, we also present the relationships among study

163 variables when within-person and between-person influences are not statistically disentangled to 164 highlight the important implications of exploring these divergent processes. These are for 165 comparative purposes and reflect an abstruse mix of within-person and between-person 166 influences; therefore, we offered no hypotheses for this aspect of the study.

\section{Method}

168 Participants and Context

A charitable organization in the UK organized the delivery of a 12 hour per week soccer

170 and education program over an 11-week period. The program aimed to build confidence, extend

171 social networks and develop skills, qualifications and goals for moving into educational and

172 vocational pathways through a combination of soccer coaching and employability support. The

173 soccer component of the program was delivered by one full-time coach who structured and

174 facilitated coaching sessions that aimed to develop skills that participants could transfer into

175 employment or education following the program (e.g., organization of coaching sessions,

176 communication, and teamwork). The educational element provided participants with support and

177 guidance to help them seek employment and educational opportunities (e.g., college application 178 support, interview skills).

All 39 participants of the program (33 male, 6 female; $M$ age $=22.88$ years, $S D=5.94$,

180 range $=18-51$ years) agreed to participate in the study. Participants were predominately White

181 British (94\%), followed by mixed White and Asian (3\%), and Black African (3\%). Prior to the

182 study, 66\% of participants were receiving state benefits, and $41 \%$ of participants reported having 
183 no formal qualifications. Participants were all unemployed at the time of the study (length of 184 unemployment ranged from 2 months to 30 months) and lived in an urban area with the highest 185 share of deprived zones in Scotland (Scottish Executive National Statistics, 2006). Participants 186 were recruited to the program by outreach workers who engaged with local communities and 187 referral agents, such as job centers and local youth services. Only individuals who were 188 189 190 191 192 193 194 195 196 199 acceptable. unemployed at the beginning of the study were eligible to attend the program.

Although our Level 2 sample size (39 participants, with 11 observations at Level 1) seems modest if we were to employ traditional single-level analyses (e.g., ordinary least squares regression), it is important to note the suitability of multilevel modeling for such sample sizes. A simulation study showed that there was no meaningful bias associated with fixed regression coefficients when using any combination of 30, 50 or 100 Level 2 units, and 5, 30 or 50 Level 1 observations (Maas \& Hox, 2005). The same study also examined bias in standard errors by inspecting whether true values lay outside confidence interval boundaries during simulations (i.e., noncoverage). With a sample of 30 Level 2 units, a noncoverage rate of 6\% was found in comparison to 5\% with a sample of 100 Level 2 units. Maas and Hox regarded this difference in coverage as 'unimportant' (pp. 89). In view of this simulation study, we deemed our sample size

\section{Procedure}

Approval was granted from a university ethics committee and full consent was obtained from all study participants. Participants were informed that only the research team would have access to their responses and under no circumstances would their answers impact upon their future involvement in the program. Following a brief explanation of the study, the participants completed the week one questionnaire under the supervision of the first author and at least one 
member of the program staff. Each participant completed the same multi-section questionnaire once per week and on the same day each week. These were completed before the morning session or during one of the employability support sessions. To maintain anonymity, participant responses at different time points were matched using a coding system using only the participants' date of birth.

\section{Measures}

Perceptions of autonomy support. Participants were asked to evaluate the autonomy support received from the coaching staff by responding to three adapted items from the Relevance subscale of the Teacher as Social Context questionnaire (Belmont, Skinner, Wellborn, \& Connell, 1992). Participants were asked to respond to the following statements, "the coach talks about how we can use things we learn in normal life", "the coach explains why what I do in the sport program is important to me", and "the coach encourages us to find out how what we do in the sport program could be useful to us in normal life” on a 4-point scale, anchored by 1 (not at all true) and 4 (very true). These items were chosen because demonstrating the relevance of activities has been suggested to be an effective strategy when coaching socially disadvantaged youth, whereas other dimensions of autonomy support, particularly the provision of choice, may not be so effective with this population (Cowan, Taylor, McEwan, \& Baker, 2012). This subscale has demonstrated acceptable internal consistency previously (Belmont et al., 1992). Identified and introjected regulation to participate in the program. Participants’ identified and introjected regulation was measured by adapting items from the Multidimensional Work Motivation Scale (Gagné et al., 2014) to program participation, as opposed to work participation. Participants responded to the question "I attend the program..." followed by three items for each subscale, measuring identified regulation (e.g., "Because I personally consider it 
229 important to put effort into the program"), and introjected regulation (e.g., "Because it makes me 230 feel proud of myself”). These items were answered using a 7-point scale, anchored by 1 (Not at 231 all) and 7 (Completely). Gagné et al. (2014) reported acceptable internal consistency and 232 factorial validity of these subscales.

Self-esteem. To reduce the cognitive and temporal burden on participants and minimize 234 the risk of noncompliance or attrition (Bolger, Davis, \& Rafaeli, 2003), participants were asked 235 to report their levels of self-esteem by responding to the five positively worded items from the 236 Rosenberg (1965) self-esteem scale (e.g., "I am able to do things as well as most other people”).

237 Shortening measurement scales is a common and often necessary step for researchers using 238 repeated measures designs (Bolger et al., 2003) and this was particularly necessary given the lack 239 of formal education within the present sample. These items were answered using a 4-point scale, 240 anchored by 1 (Strongly Disagree) and 4 (Strongly Agree) and have well-established reliability 241 and validity (e.g., Flynn-Corwyn, 2000; Rosenberg, 1965).

Self-efficacy towards coaching. We asked participants to report their levels of self-

243 efficacy towards coaching by responding to five items from the New General Self-Efficacy Scale 244 (Chen, Gully, \& Eden, 2001) adapted to coaching. We chose this questionnaire because existing 245 coaching-efficacy questionnaires emphasized competitive coaching, rather than general 246 coaching. As none of the participants had previous experience of coaching, we included a 247 statement preceding the items asking participants to consider the future (i.e., "Consider a time 248 when you will be coaching in the future and please respond to the following statements”). An 249 example item was “I believe I can succeed at coaching”. We omitted three items from the full 250 scale because they did not possess adequate face validity with the context of the present study in 251 mind (i.e., efficacy towards future coaching). These items were answered using a 5-point scale, 
252 anchored by 1 (Strongly Disagree) and 5 (Strongly Agree) and have demonstrated reliability and 253 factorial validity (Chen et al., 2001).

254 Data Analysis

We constructed multilevel models using MLwiN software (version 2.25; Rasbash, 256 Browne, Healy, Cameron, \& Charlton, 2012) to explore the study hypotheses. We used this 257 method of analysis because of the hierarchical structure of the data, that is, measurement time 258 points were nested within program participants. Multilevel analysis takes into account this 259 clustered data by modeling separate, but related equations at both the within-person and 260 between-person levels resulting in a more accurate estimation of the parameters and statistical 261 significance (Hox, 2010). An advantage of multilevel modeling is its robustness against missing 262 data and unbalanced measurements across participants are not deemed to cause any problems 263 with the data (Hox, 2010).

264 First, we explored the degree of variance in the study variables at the within-person and 265 between-person levels by calculating intraclass correlation coefficients (ICCs) obtained from 266 intercept-only model parameters. To explore the relationships between autonomy support and 267 motivation, we constructed conditional models for each motivational regulation (model 1: 268 identified regulation; model 2: introjected regulation), with coach autonomy support as a grand 269 mean centered predictor variable in the Level 1 equation. This variable in isolation represents an 270 ambiguous mixture of the Level 1 (i.e., within-person) and Level 2 (i.e., between-person)

271 associations (Enders \& Tofighi, 2007) between autonomy support and motivation, thus, it serves 272 as an indicator of potentially spurious conclusions when within-person and between-person 273 effects are not disaggregated. 
The next stage of our analyses involved disaggregating these within-person and betweenperson associations by following the procedures outlined by Enders and Tofighi (2007) (model 3: identified regulation; model 4: introjected regulation). First, we centered participants’ aggregate (i.e., mean score across the course of the program) autonomy support scores on the grand mean and entered it into the Level 2 equation. This provides an accurate estimation of the between-person associations between average levels of autonomy support and the outcome variable. In other words, does an individual with higher average perceptions of autonomy support report higher motivational regulations, compared to a participant who perceives lower coach support? We then included a time-varying autonomy support variable into the Level 1 equation, which was also centered on the grand mean. The inclusion of the Level 2 aggregate score removes between-person variation from the Level 1 variable, leaving an accurate estimation of the influence of weekly within-person deviations from a participant's average score (Marsh et al., 2012). This represents whether fluctuations around an individual's average levels of autonomy support are associated with fluctuations in motivational regulations. To test the relationships among the two types of motivation, self-esteem and self-efficacy, similar models were constructed with the two motivational regulations entered into the Level 1 equation as an indicator of potentially spurious relationships (model 5: self-esteem; model 7: self-efficacy), and then into the Level 2 equation to disaggregate within-person and between-person relationships (model 6: self-esteem; model 8: self-efficacy).

\section{Results}

\section{Descriptive Statistics, Cronbach’s Alpha Coefficients, ICCs, and Bivariate Correlations}

One percent of the data was missing but due to the advantages of multilevel modeling, it was not imputed or treated in any way. Table 1 shows the means, standard deviations, 
297 Cronbach’s alpha coefficients, ICCs, and bivariate correlations for each variable. In general, 298 participants reported all study variables above the midpoint of the scale and all variables had 299 acceptable internal consistency (i.e., $\alpha>.70$ ). The ICCs indicated that between 50 and $68 \%$ of 300 the variance in the study variables was attributable to the between-person level, therefore, 301 between 32 and $50 \%$ of the variance in the study variables was attributable to the within-person 302 level. This justifies our rationale for employing multilevel modeling and demonstrates substantial 303 variance at both levels.

304 Autonomy support as a predictor of identified and introjected motivational regulations The results of these models are presented in Table 2. In the models that did not distinguish between within-person changes and between-person differences, autonomy support positively predicted identified regulation (model 1) and introjected regulation (model 2). When differentiating between the two types of relationship, within-person changes in perceptions of autonomy support positively predicted identified regulation (model 3) and introjected regulation

310 (model 4). Between-person differences in autonomy support positively predicted identified 311 regulation (model 3) but not introjected regulation (model 4).

312 Motivational regulations as predictors of self-esteem and self-efficacy

The results of these models are presented in Table 3. In the model that did not distinguish 314 between within-person changes and between-person differences, identified regulation positively 315 predicted self-esteem, but introjected regulation did not (model 5). When differentiating between 316 the two levels (model 6), within-person changes in introjected regulation positively predicted 317 self-esteem but identified regulation did not. In contrast, between-person levels of introjected 318 regulation negatively predicted self-esteem, whereas identified regulation positively predicted 319 self-esteem. 
Regarding self-efficacy, identified regulation and introjected regulation positively predicted self-efficacy when within- and between-person levels were not disaggregated (model 7). When the different relationships were considered (model 8) within-person changes in identified and introjected regulation positively predicted self-efficacy. In contrast, betweenperson differences in identified regulation positively predicted self-efficacy, whereas introjected regulation negatively predicted self-efficacy.

\section{Discussion}

The purpose of this study was to highlight the importance of disaggregating withinperson versus between-person processes when exploring the internalization of introjected and identified motives. Specifically, we longitudinally examined socially disadvantaged adults’ perceptions of autonomy support, their motives for participation in a sport and education program, self-esteem and self-efficacy towards future coaching roles. The general pattern of findings revealed that within-person changes in both types of internalized motivation had positive associations with one's self-esteem and self-efficacy. However, sustained levels of identification seemed to be beneficial for these adults' self-esteem and efficacy, whereas continued levels of introjection may be detrimental. In the following sections we discuss the specific findings and offer implications for theory and future research.

\section{Autonomy support as a predictor of motivational regulations}

Self-determination theorists propose that the interpersonal style of individuals in leadership positions (e.g., teachers, coaches, parents) can facilitate or frustrate the internalization process amongst those under their supervision. In accordance with our hypothesis, our results suggest that an individual who experiences an increase in autonomy support, relative to their own average experiences, may display higher identified and introjected regulation. For example, 
343 when a coach provides a meaningful rationale for an activity, the individual may value the

344 activity more but also want to complete the activity so as not to let the coach down. In contrast,

345 sustained levels of autonomy support were only positively associated with identified regulation,

346 and not introjected regulation (although it should be noted that the coefficients were of a similar

347 magnitude and the statistical significance of the coefficient related to introjected regulation was

348 borderline).

349 This implies that continued autonomy support is likely to facilitate more optimal forms of 350 internalization (Deci \& Ryan, 1987; Williams \& Deci, 1996); however, this important theoretical 351 postulate may be masked if researchers do not consider the different within-person and between352 person processes associated with receiving autonomy support. An example is the use of cross353 sectional studies examining links between autonomy support and motivational regulations. For 354 instance, reported positive indirect relationships between social factors and introjected regulation 355 in school physical education (Ntoumanis, 2001; Standage, Duda, \& Ntoumanis, 2005) may be a 356 result of the inability to tease out within- and between-person relationships in cross-sectional 357 studies. Another important implication may exist for interventions which have short term impact 358 but effects dissipate over time. An intervention that successfully increases individuals’ 359 perceptions of autonomy support in the short term may facilitate both types of internalized 360 motivation. However, it is only those interventions which sustain those perceptions of autonomy 361 support over time which will lead to optimal internalization.

362 Motivational regulations as predictors of self-esteem and self-efficacy

363 Our results indicate it is important to distinguish between within-person and between364 person effects when exploring the relationship between internalization, self-esteem and self365 efficacy. Perhaps most intriguingly, our findings may shed light on the previous equivocal 
366 findings concerning introjected regulation and associated outcomes (e.g., Edmunds et al., 2006;

367 Pelletier et al., 2001). A relative increase in introjected motives for participation in the program

368 was associated with higher overall feelings of worth (i.e., self-esteem) and future effectiveness in 369 a specific context (i.e., self-efficacy towards coaching). These findings in isolation may imply

370 that similar programs should attempt to foster feelings of contingent self-worth and ego-

371 involvement to enhance the likelihood of positive outcomes. Moreover, this result seems to

372 concur with the notion that motivation to preserve one's social significance is closely associated

373 with positive self-esteem (Leary \& Baumeister, 2000). However, those individuals experiencing

374 higher sustained introjection within the program reported lower self-esteem and self-efficacy,

375 compared to participants with less introjected motivation. This provides substance to the

376 proposal that the facilitation of motives, such as ego-involvement or guilt and shame avoidance,

377 may elicit a short term positive response, but eventually sustained levels of high introjected

378 regulation may lead to negative consequences (Koestner et al., 1996) in the shape of lower self-

379 esteem and self-efficacy.

380 In contrast to introjected regulation, within-person increases in identified regulation were 381 associated with higher self-efficacy, and higher sustained identified regulation was related with 382 higher self-esteem and efficacy. These findings are consistent with research concerning the 383 adaptive outcomes associated with identified regulation (Edmunds et al., 2006; Losier \& 384 Koestner, 1999) and imply that relative within-person changes and individual differences in 385 identified regulation are fundamental to self-esteem and efficacy. To our knowledge this is the 386 first description of the different processes that may occur at these diverse levels, and has 387 important repercussions for the development of self-esteem and self-efficacy. Aligned with 388 organismic integration theory (Deci \& Ryan, 2000), only fuller types of internalization seem to 
389 have benefits for the self over a sustained period of time, and forestalled internalization

390 processes may be detrimental for one’s esteem and efficacy, despite some short term benefits.

391 Importantly, our analysis which did not differentiate between these two processes indicates that 392 potentially opposite effects may be hidden if researchers choose not to consider these divergent 393 mechanisms.

\section{Future directions and limitations}

Our study identified the importance of differentiating between within- and between-

396 person relationships within internalization processes; however, the study is not without its

397 limitations. Although we provide evidence that the sample size in this study is acceptable for 398 exploring fixed effects (Maas \& Hox, 2005), a larger sample size would enable researchers to 399 explore random effects that could establish whether the relationships observed in this study are 400 heterogeneous across participants. Future attempts to replicate our results with larger samples 401 may also enhance the generalizability and extend our findings. Second, we wanted to explore 402 internalization processes in a cohort where self-esteem and self-efficacy have been shown to 403 have important implications (e.g., more likely to gain employment; Eden \& Aviram, 1993), 404 however, it may be worth attempting to replicate these findings in different samples taking part 405 in different activities. For example, the implications of introjected regulation in team 406 environments where not letting others down can be a powerful influence, such as military or 407 sport, may be very different for one’s self-esteem and self-efficacy. Finally, our findings

408 demonstrated that autonomy support may be associated with both types of internalization in 409 some circumstances; therefore, it may be prudent to explore conditions in which autonomy 410 support develops identified, rather than introjected motives. 
412 our study variables offers unique insight into the internalization of an activity and its potential

413 impact upon self-esteem and self-efficacy. In general, results revealed the within-person changes

414 in introjected motivation toward an educational program may have some short term benefits;

415 however, over a sustained period of time introjection may be maladaptive for one’s self-esteem

416 and self-efficacy. In contrast, sustained autonomy support and identified regulation may have

417 benefits for self-esteem and efficacy beliefs towards future coaching roles of socially

418 disadvantaged unemployed adults.

419

420

421

422

423

424

425

426

427

428

429

430

431

432

433 
434

435

436

437

438

439

440

441

442

443

444

445

446

447

448

449

450

451

452

453

454

455

\section{References}

Assor, A., Vansteenkiste, M., \& Kaplan, A. (2009). Identified versus introjected approach and introjected avoidance motivations in school and in sports: The limited benefits of selfworth strivings. Journal of Educational Psychology, 101, 482-497.

Bandura, A. (1997). Self-efficacy: The exercise of control. New York: Freeman.

Belmont, M., Skinner, E., Wellborn, J., \& Connell, J. (1992). Teacher as social context: A measure of student perceptions of teacher provision of involvement, structure and autonomy support. Rochester, NY: University of Rochester.

Bolger, N., Davis, A., \& Rafaeli, E. (2003). Diary methods: Capturing life as it is lived. Annual Review of Psychology, 54, 579-616.

Bono, J. E. \& Judge, t. A. (2003). Core self-evaluations: A review of the trait and its role in job satisfaction and job performance. European Journal of Personality, 17, S5-S18.

Chen, G., Gully, S. M., \& Eden, D. (2001). Validation of a new general self-efficacy scale. Organizational Research Methods, 4, 62-83. doi:10.1177/109442810141004

Cowan, D., Taylor, I. M., \& Baker, J. S. (2012). Predictors of intra-individual change in the psychological development of disadvantaged youth over the course of an educational sports programme. [Abstract]. European College of Sport Science Congress 2012.

Curran, P. J. \& Bauer, D. J. (2011). The disaggregation of within-person and between-person effects in longitudinal models of change. Annual Review of Psychology, 62, 583-619. doi:10.1146/annurev.psych.093008.100356

Deci, E. L., \& Ryan, R. M. (1985). Intrinsic motivation and self-determination in human behaviour. New York: Plenum. 
456 Deci, E. L., \& Ryan, R. M. (1987). The support of autonomy and the control of behavior.

457

458

459

460

461

462

463

464

465

466

467

468

469

470

471

472

473

474

475

476

477 Journal of Personality and Social Psychology, 53, 1024-1037.

Deci, E. L., \& Ryan, R. M. (2000). The “what” and “why” of goal pursuits: Human needs and the self-determination of behavior. Psychological Inquiry, 11, 227-268. doi:10.1207/S15327965PLI1104_01

Deci, E. L., \& Ryan, R. M. (2008). Facilitating optimal motivation and psychological well-being across life’s domains. Canadian Psychology, 49, 14-23.

Eden, D., \& Aviram, A. (1993). Self-efficacy training to speed reemployment: Helping people to help themselves. Journal of Applied Psychology, 78, 352-360. doi:10.1037//00219010.78.3.352

Edmunds, J., Ntoumanis, N., \& Duda, J. L. (2006). A test of self-determination theory in the exercise domain. Journal of Applied Social Psychology, 36, 2240-2265. doi:10.1111/j.0021-9029.2006.00102.x

Enders, C. K., \& Tofighi, D. (2007). Centering predictor variables in cross-sectional multilevel models: A new look at an old issue. Psychological Methods, 12, 121-138. doi:10.1037/1082-989X.12.2.121

Flynn-Corwyn, R. (2000). The factor structure of global self-esteem among adolescents and adults. Journal of Research in Personality, 34, 357-379. doi:10.1006/jrpe.2000.2291

Gagné, M., Forest, J., Vansteenkiste, M., Crevier-Braud, L., Van den Broeck, A., Aspeli, A. K., Bellerose, J., Benabou, C., Chemolli, E., Güntert, S. T., Halvari, H., Laksmi-Indiyastuti, D., Johnson, P., Molstad, M., Naudin, M., Ndao, A., Hagen Olafson, A., Roussel, P., Wang, Z., \& Westbye, M. (2014) The Multidimensional Work Motivation Scale: Validation 
478

479

480

481

482

483

484

485

486

487

488

489

490

491

492

493

494

495

496

497

498

499

500

evidence in seven languages and nine countries. European Journal of Work and Organizational Psychology. doi:10.1080/1359432X.2013.877892

Harris, E., Lum, J., Rose, V., Morrow, M., Comino, E., \& Harris, M. (2002). Are CBT interventions effective with disadvantaged job-seekers who are long-term unemployed? Psychology, Health \& Medicine, 7, 401-410. doi:10.1080/1354850021000015221

Hox, J. J. (2010). Multilevel analysis. Techniques and applications. 2nd Edition. New York: Routledge.

Koestner, R., Losier, G, F., Vallerand, R. J., \& Carducci, D. (1996). Identified and introjected forms of political internalization: Extending self-determination theory. Journal of Personality and Social Psychology, 70, 1025-1036. doi:10.1037//0022-3514.70.5.1025

Leary, M. R., \& Baumeister, R. F. (2000). The nature and function of self-esteem: Sociometer theory. In M.P. Zanna (Ed.), Advances in experimental social psychology (Vol. 32, pp. 162). San Diego, CA: Academic Press.

Losier, G. F., \& Koestner, R. (1999). Intrinsic versus identified regulation in distinct political campaigns: The consequences of following politics for pleasure versus personal meaningfulness. Personality and Social Psychology Bulletin, 25, 287-298. doi:10.1177/0146167299025003002

Maas, C. J. M \& Hox, J. J. (2005). Sufficient sample sizes for multilevel modeling. Methodology, 1, 86-92. doi:10.1027/1614-1881.1.3.86

Marsh, H. W., Lüdtke, O., Nagengast, B., Trautwein, U., Morin, A. J. S., Abduljabbar, A. S., \& Koller, O. (2012). Classroom climate and contextual Effects: Conceptual and methodological issues in the evaluation of group-level effects. Educational Psychologist, 47, 106-124. 
501 Ntoumanis, N. (2001). A self-determination approach to the understanding of motivation in $502 \quad$ physical education. British Journal of Educational Psychology, 71, 225-242.

503 Pelletier, L. G., Fortier, M. S., Vallerand, R. J., \& Brière, N. M. (2001). Associations among 504 perceived autonomy support, forms of self-regulation, and persistence: A prospective study. Motivation and Emotion, 25, 279-306. doi:10.1023/A:1014805132406

506

507

508

509

510

511

512

513

514

515

516

517

518

519

520

521

522

Rasbash, J., Browne, W.J., Healy, M., Cameron, B., Charlton, C. M. J. (2012). MLwiN Version 2.25 .

Rosenberg, M. (1965). Society and the adolescent self-image. Princeton, NJ, Princeton University Press.

Ryan, R. M. (1993). Agency and organization: Intrinsic motivation, autonomy and the self in psychological development. In J. Jacobs (Ed.), Nebraska symposium on motivation: Developmental perspectives on motivation, Vol. 40 (pp. 1-56). Lincoln, NE: University Of Nebraska Press.

Ryan, R. M., \& Brown, K. W. (2003). Why we don't need self-esteem: On fundamental needs, contingent love, and mindfulness. Psychological Inquiry, 14, 71-76.

Scottish Executive National Statistics (2006). SIMD general report. Edinburgh: Scottish Executive.

Standage, M., Duda, J. L., \& Ntoumanis, N. (2005). A test of self-determination theory in school physical education. British Journal of Educational Psychology, 75, 411-433.

Taylor, I. M., \& Ntoumanis, N. (2007). Teacher motivational strategies and student selfdetermination in physical education. Journal of Educational Psychology, 99, 747-760. doi:10.1037/0022-0663.99.4.747 
523 Teixeira, P. J., Carraça, E. V., Markland, D. A., Silva, M. N., \& Ryan, R. M. (2012). Exercise, 524 physical activity, and self-determination theory: A systematic review. International

525 526 527 528 529 530 531 532 533 536 537 538 539 540

$541{ }^{1}$ Self-determination theorists also propose different motivational regulations, including intrinsic 542 (e.g., acting out of inherent interest or enjoyment) and external regulations (e.g., being driven by 543 external contingencies, such as reward or punishment). We did not examine these regulations as 544 the relationships among these motives, autonomy support and self-evaluations were not expected 545 to demonstrate nuanced differences across within-person and between-person levels of analysis. 
546 Table 1

547 Range of Scales, Means, Standard Deviations, Cronbach's Alphas, Intraclass Correlation Coefficients (ICC), and Bivariate

548 Correlations of all Study Variables

\begin{tabular}{|c|c|c|c|c|c|c|c|c|c|c|}
\hline \multirow{2}{*}{\multicolumn{2}{|c|}{ Variable }} & \multirow{2}{*}{$\begin{array}{l}\text { Scale } \\
\text { Range }\end{array}$} & \multirow[b]{2}{*}{$\operatorname{Mean}(S D)$} & \multirow[b]{2}{*}{$\alpha_{\text {(Median) }}$} & \multirow[b]{2}{*}{ ICC } & \multicolumn{5}{|c|}{ Bivariate Correlations } \\
\hline & & & & & & $(1)$ & $(2)$ & (3) & $(4)$ & (5) \\
\hline 1. & $\begin{array}{l}\text { Autonomy } \\
\text { Support }\end{array}$ & $1-4$ & $3.26(.58)$ & .82 & .67 & - & $.34 *$ & .24 & $.40 *$ & $.39 *$ \\
\hline 2. & $\begin{array}{l}\text { Identified } \\
\text { Regulation }\end{array}$ & $1-7$ & $5.11(1.15)$ & .89 & .65 & & - & $.48 * *$ & .10 & $.36^{*}$ \\
\hline 3. & $\begin{array}{l}\text { Introjected } \\
\text { Regulation }\end{array}$ & $1-7$ & $4.17(1.29)$ & .77 & .68 & & & - & .17 & .26 \\
\hline 4. & $\begin{array}{l}\text { Self- } \\
\text { Esteem }\end{array}$ & $1-4$ & 3.18(.47) & .79 & .59 & & & & - & $.60 * *$ \\
\hline 5. & $\begin{array}{l}\text { Self- } \\
\text { Efficacy }\end{array}$ & $1-5$ & $4.04(.51)$ & .86 & .50 & & & & & - \\
\hline
\end{tabular}

Note.. ${ }^{*} . p<.05 .{ }^{* *} p<.01$ 
550 Table 2

551 Autonomy support as a predictor of identified and introjected motivational regulations

\begin{tabular}{|c|c|c|c|c|}
\hline \multirow{2}{*}{ Predictors \& Intercept } & \multicolumn{2}{|c|}{$\begin{array}{l}\text { Identified } \\
\text { regulation }\end{array}$} & \multicolumn{2}{|c|}{$\begin{array}{l}\text { Introjected } \\
\text { regulation }\end{array}$} \\
\hline & $\boldsymbol{b}$ & $S E$ & $\bar{b}$ & $S E$ \\
\hline Model not disaggregated & \multicolumn{2}{|c|}{ Model 1} & \multicolumn{2}{|c|}{ Model 2} \\
\hline Intercept & 5.07 & $.14 * * *$ & 4.15 & $.17 * * *$ \\
\hline Autonomy Support & .40 & $.11 * * *$ & .35 & $.12 * *$ \\
\hline Level 1 error variance & .46 & $.04 * * *$ & .54 & $.05^{* * *}$ \\
\hline Level 2 error variance & .70 & $.17 * * *$ & 1.05 & $.25 * * *$ \\
\hline -2 Log-likelihood & \multicolumn{2}{|c|}{793.911} & \multicolumn{2}{|c|}{833.775} \\
\hline
\end{tabular}

Model disaggregated

Intercept

Within-person changes

Autonomy Support

Between-person differences

.28

$.12 *$

.27

$.13^{*}$

Model 3

Model 4

$5.08 \quad .13^{* * *} \quad 4.16 \quad .16^{* * *}$

Autonomy Support

.88

$.29 * *$

.68

.37

Level 1 error variance

.46

$.04 * * *$

$.53 \quad .05 * * *$

Level 2 error variance

.57

$.14 * * *$

$.96 \quad .23 * * *$

-2 Log-likelihood

785.432

830.458 
553 Table 3

554 Motivational regulations as predictors of self-esteem and self-efficacy

\begin{tabular}{|c|c|c|c|c|}
\hline \multirow[b]{2}{*}{ Predictors \& Intercept } & \multicolumn{2}{|c|}{ Self-Esteem } & \multicolumn{2}{|c|}{ Self-Efficacy } \\
\hline & $\boldsymbol{b}$ & $S E$ & $\boldsymbol{b}$ & $S E$ \\
\hline Model not disaggregated & \multicolumn{2}{|c|}{ Model 5} & \multicolumn{2}{|c|}{ Model 7} \\
\hline Intercept & 3.18 & $.06 * * *$ & 4.05 & $.05^{* * *}$ \\
\hline Identified regulation & .06 & $.03 *$ & .11 & $.03^{* *}$ \\
\hline Introjected regulation & .04 & .03 & .08 & $.03 *$ \\
\hline Level 1 error variance & .08 & $.01 * * *$ & .13 & $.01 * * *$ \\
\hline Level 2 error variance & .12 & $.03 * * *$ & .10 & $.03 * * *$ \\
\hline -2 Log-likelihood & \multicolumn{2}{|c|}{217.910} & \multicolumn{2}{|c|}{329.012} \\
\hline Model disaggregated & \multicolumn{2}{|c|}{ Model 6} & \multicolumn{2}{|c|}{ Model 8} \\
\hline Intercept & 3.18 & $.05 * * *$ & 4.05 & $.05 * * *$ \\
\hline \multicolumn{5}{|l|}{ Within-person changes } \\
\hline Identified regulation & .05 & .03 & .08 & $.03 *$ \\
\hline Introjected regulation & .06 & $.03 *$ & .11 & $.03^{* *}$ \\
\hline \multicolumn{5}{|l|}{ Between-person differences } \\
\hline Identified regulation & .29 & $.10^{* *}$ & .36 & $.09 * * *$ \\
\hline Introjected regulation & -.28 & $.09 * *$ & -.31 & $.08 * * *$ \\
\hline Level 1 error variance & .08 & $.01 * * *$ & .13 & $.01 * * *$ \\
\hline Level 2 error variance & .09 & $.02 * * *$ & .06 & $.02 * * *$ \\
\hline -2 Log-likelihood & \multicolumn{2}{|c|}{207.638} & \multicolumn{2}{|c|}{313.613} \\
\hline
\end{tabular}

Note: $* p<.05, * * p<.01, * * * p<.001$ 